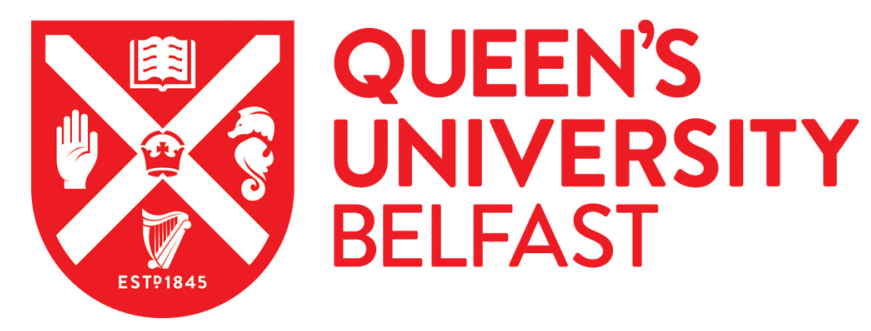

\title{
Unmet need for mental health medication within the migrant population of Northern Ireland: a record linkage study
}

Patel, K., Bosqui, T., Kouvonen, A., Donnelly, M., Väänänen, A., Bell, J., \& O'Reilly, D. (2021). Unmet need for mental health medication within the migrant population of Northern Ireland: a record linkage study. Journal of Epidemiology and Community Health, 75(3), 245-250. https://doi.org/10.1136/jech-2019-212774

Published in:

Journal of Epidemiology and Community Health

Document Version:

Publisher's PDF, also known as Version of record

Queen's University Belfast - Research Portal:

Link to publication record in Queen's University Belfast Research Portal

Publisher rights

Copyright 2021 the authors.

This is an open access Creative Commons Attribution-NonCommercial License (https://creativecommons.org/licenses/by-nc/4.0/), which permits use, distribution and reproduction for non-commercial purposes, provided the author and source are cited.

\section{General rights}

Copyright for the publications made accessible via the Queen's University Belfast Research Portal is retained by the author(s) and / or other copyright owners and it is a condition of accessing these publications that users recognise and abide by the legal requirements associated with these rights.

Take down policy

The Research Portal is Queen's institutional repository that provides access to Queen's research output. Every effort has been made to ensure that content in the Research Portal does not infringe any person's rights, or applicable UK laws. If you discover content in the Research Portal that you believe breaches copyright or violates any law, please contact openaccess@qub.ac.uk. 


\title{
The Unmet Need for Mental Health
}

\section{Medication within the Migrant Population of Northern Ireland - A Record Linkage}

\section{Study}

\section{Kishan Patel ${ }^{1}$, Tania Bosqui ${ }^{1,2}$, Anne Kouvonen ${ }^{1,3,4}$, Michael Donnelly ${ }^{1}$, Ari Väänänen ${ }^{5,6}$, Justyna Bell ${ }^{7}$, Dermot O'Reilly,}

\author{
${ }^{1}$ Administrative Data Research Centre - Northern Ireland, Centre for Public Health, Queen's \\ University Belfast, Belfast, UK \\ ${ }^{2}$ Department of Psychology, American University of Beirut, Beirut, Lebanon \\ ${ }^{3}$ Faculty of Social Sciences, University of Helsinki, Helsinki, Finland \\ ${ }^{4}$ SWPS University of Social Sciences and Humanities in Wroclaw, Wroclaw, Poland \\ ${ }^{5}$ Finnish Institute of Occupational health, Helsinki, Finland \\ ${ }^{6}$ School of Social Policy, Sociology and Social Research, University of Kent, UK \\ ${ }^{7}$ Norwegian Social Research (NOVA), Oslo Metropolitan University, Oslo, Norway \\ ${ }^{8}$ UKCRC Centre of Excellence for Public Health (Northern Ireland), Queen's University Belfast, \\ Belfast, UK
}

Corresponding author: Kishan Patel; Centre for Public Health, Royal Victoria Hospital, Grosvenor Road, Belfast, Northern Ireland, BT12,6BA; kpatel05@qub.ac.uk; 07779992070.

Key Words: Mental Health; Migration; Unmet Need; Record Linkage; Public Health 


\section{ABSTRACT}

Background: Migrant populations are particularly at risk of not receiving the care for mental illhealth that they require for a range of reasons, including language and other barriers to health service access. This record linkage study compares, for migrant and settled communities, the likelihood that a person in Northern Ireland with poor mental health will receive psychotropic medication.

Methods: A cohort of 78,267 people aged 16-64 (including 1,736 migrants) who reported chronic poor mental health in the 2011 Census records was followed for 15 months by linkage to a centralised prescribing dataset to determine rates of pharmacological treatment. Logistic regression analyses quantified the relationship between psychotropic medication uptake and migrant status, while accounting for relevant demographic and socio-economic factors.

Results: Overall, $67 \%$ of migrants with chronic poor mental health received at least one psychotropic medication during the study period, compared to $86 \%$ for the settled population; this equates to an odds ratio of OR $0.32(95 \% \mathrm{Cl} 0.29-0.36)$ in the fully adjusted models. Adjustment for English proficiency did not significantly alter these models. There was also considerable variation between individual migrant groups.

Conclusion: Although this study suggests substantial unmet need for treatment of poor mental health amongst the migrant population of Northern Ireland, further qualitative studies are required to better understand how different migrant groups respond to mental ill-health. 


\section{What is already known on this subject?}

The unmet need migrants that require mental health treatment experience is a growing concern, and a public health issue that exists for a number of reasons. It is therefore important that the extent of, and the reasons for, the disparity between mental health care access amongst migrant and settled communities is further explored.

\section{What this study adds?}

This study quantifies the unmet need for migrant mental healthcare in Northern Ireland, and discusses the reasons for individual migrant groups' lack of mental healthcare access. The study also suggests more migrant group-specific policy changes in order to successfully target such heterogeneous migrant populations. 


\section{INTRODUCTION}

It is recognised that many people with poor mental health do not receive the care they require.

This has been attributed to a variety of reasons including stigma, self-medication, lack of culturally sensitive healthcare services, and difficulties accessing health care ${ }^{1-3}$. Migrant populations are particularly at risk and, following a systematic review, the 'EU contribution to the World Mental Health Surveys Initiative' (EU-WMH) recommended specifically studies to research the unmet mental health care needs of migrant populations ${ }^{4}$. However, research in this area remains sparse.

It is known that there are differences in how mental health is perceived. The somatisation of mental health symptoms is especially common in non-Western populations ${ }^{5,6}$ and may impede help-seeking amongst ethnic minorities, and especially the use of mental-health care that is viewed as part of a 'medical' service'. Mental health care help-seeking is negatively influenced by stigma and a feeling of shame ${ }^{8}$, but is also culturally determined - some cultures are known to be particularly prone to maintaining secrecy about mental ill-health and avoid discussions with health care professionals and family ${ }^{9}$. Furthermore, some migrants may hold negative attitudes towards medication, believing for example that psychotropic medication supplied within their adopted countries is less effective for them than for members of the settled population ${ }^{10}$. Language barriers may prevent migrants from accurately describing their condition and receiving suitable diagnoses ${ }^{11}$.

On the other hand, migrants who acknowledge that they need help may face multiple hurdles accessing care and navigating the complexities of the new healthcare system ${ }^{12}$. In the UK, migrants need to first register for a medical card before they can access health services ${ }^{13}$, which may not be obvious, as there are no induction programmes for migrants. Furthermore, policies relating to migrant healthcare entitlements often use terminology that migrants may find difficult to understand ${ }^{14}$ and can change, adding to their uncertainties ${ }^{15}$. Poor 'cultural competence' is another barrier to healthcare - Department of Health surveys show that people from Pakistani, Indian and Bangladeshi backgrounds reported significantly poorer healthcare experiences than White British or Irish patients ${ }^{16}$. There is a suggestion that ethnicity is considered within a healthcare context primarily in terms of legal compliance, rather than with the aim of accurately determining differing health care needs ${ }^{17}$. Finally, the relatively higher proportion of Black and minority ethnic populations that are diagnosed with mental disorders and subsequently sectioned under the Mental Health Act may engender a sense of distrust and feelings of discrimination which, in turn, may deter help-seeking behaviours ${ }^{18}$.

Previous research concerning the unmet need for mental health service access for migrant populations is limited, both in quantity and quality. Studies are often small scale, and only 
sample subsets of the populations in question. In addition, most research is restricted to the analysis of single migrant groups ${ }^{19,20}$, uses ethnicity as a proxy for migrant status ${ }^{21}$, or does not focus specifically on mental health ${ }^{22}$. Though unmet need for treatment of people with common mental disorders has been highlighted in the UK previously ${ }^{23,24}$, no study in the UK has focussed on the unmet needs of migrant populations.

The aim of this study was to assess and compare unmet mental ill-health needs in terms of use of psychotropic medication by the migrant and settled populations in Northern Ireland. 


\section{METHODS}

\section{Data Sources}

This is a record-linkage study of two population-wide datasets, the 2011 Northern Ireland Census and a centralised prescriptions database (EPD). The Census was used to define the cohort, differentiate migrants from the settled population, and provide detailed attributes of all cohort members.

\section{Defining Migrant Status}

In accordance with previous research, migrant status was based on the country of birth documented on Census record. Individuals from other parts of the United Kingdom or the Republic of Ireland were also classed with Northern Ireland residents as the 'settled population' due to the similarities and constant population interchange between these countries. The settled population therefore comprised of 76,531 individuals.

Persons were classified as migrants if they were born outside of the UK and Rol $(n=1,736)$, and stratified as per the United Nations ${ }^{25}$ and with consideration of sample sizes into the groups shown in Table 1.

The English language proficiency of migrants was also taken into account, using responses from a Census question asking, "How well can you speak English?". Those who indicated 'very well' or 'well' on a four-point Likert scale were deemed to have high English language proficiency, whereas those who indicated 'not well' or 'not at all' were deemed to have low proficiency.

\section{Defining poor mental health}

Uniquely within the UK, the Census asked: "Do you have any of the following conditions which have lasted, or are expected to last, at least 12 months?", and individuals were instructed to tick as many of the conditions that applied. A positive response for "An emotional, psychological or mental health condition (such as depression or schizophrenia)" was used to indicate a self-reported chronic mental health condition. The responses to this question has been validated in other studies and shown to predict suicide risk ${ }^{26}$.

\section{Study Population}

The cohort comprised the 78,267 (non-institutionalised) men and women aged 16-64 who reported a chronic mental health condition in the Census. This age range reduced the likelihood of proxy responses while covering the majority of migrants in Northern Ireland. 
The cohort attributes (shown in Supplementary Table 1) were drawn from the Census and included based on a priori associations with either mental ill- health prevalence, or with access to health care services.

\section{Measuring Unmet Need}

The Enhanced Prescribing Dataset (EPD) provided information on psychotropic medication prescription issued by GPs and dispensed by community pharmacists. 'Psychotropic medication' refers to the following three categories medications: anti-depressants (British National Formulary Number (BNF) 4.3)); anxiolytics and hypnotics (BNF 4.1); and anti-psychotics (BNF 4.2). For this study we define unmet need as a person with a chronic mental health problem, based on the Census response, who had not been in receipt of psychotropic medication at least once during the first quarter of 2011, (which included Census day), or in the following 12 months. We acknowledge that other forms of treatment, such as Cognitive Behavioural Therapy, have a strong evidence-base and are recommended by the National Institute for Clinical Excellence ${ }^{27}$, however, they are not widely available in Northern Ireland ${ }^{28}$, and medication represents the predominant treatment response ${ }^{29,30}$.

\section{Statistical Analysis}

Descriptive analyses, followed by logistic regression, were conducted to quantify the numbers of migrants and the settled majority that had indicated a mental health problem and the likelihood of receiving at least one psychotropic medication during the study period. A test for interaction between sex and mental health was not statistically significant $(p=0.24)$, so all results are reported for the combined sample of men and women. The models were adjusted initially for demographic factors, then to also include English language proficiency, and finally to also include chronic poor physical health and socioeconomic status. Further models stratified by region of birth.

All identifiers were removed from the dataset to provide the researchers with a de-identified research dataset containing 1,587,627 subjects with linked records. These data were held in a secure setting by NISRA (Northern Ireland Statistics and Research Agency) and made available to the research team for the purpose of this study. Ethical approval was obtained from the Office for Research Ethics Committee Northern Ireland (ORECNI; Ref: 15/WM/0212), the Research Ethics Committee for the School of Medicine, Dentistry and Biomedical Sciences at Queen's University Belfast (Ref: 14/54), and the Administrative Data Research Network (ADRN) Approvals Panel (Ref: 2014/008); and conform to the principles embodied in the Declaration of Helsinki. 


\section{RESULTS}

Overall, $86 \%$ of the settled population with chronic poor mental health received at least one psychotropic medication during the study period, compared to $67 \%$ of the equivalent population of 1,736 migrants (Table 1). Uptake of medication was generally lower for people in the youngest age groups, for men compared to women (respectively $80.4 \%$ and $89.0 \%$ ), and amongst students (circa 70-71\%). Uptake was lower still for people with low English language proficiency (69.8\% compared to $85.6 \%$ ).

These patterns were generally repeated in the results of the logistic regression models (Table 1). In the fully adjusted models, the likelihood of being on medication increased with age such that people aged over 45 were twice as likely to be on medication as those aged 16-24.

Females with poor mental health were also twice their equivalent male counterparts to be on medication ( $\mathrm{OR}_{\mathrm{adj}} 1.95$ ( $\left.95 \% \mathrm{Cl} 1.87-2.03\right)$ ). Medication levels were also lower amongst those who had never been married (ORadj $0.59(95 \% \mathrm{Cl} 0.55-0.63)$ ), and those who were separated/divorced/widowed (OR $0.80(95 \% \mathrm{Cl} 0.75-0.85))$, but higher in those who had poorer physical health (OR $\operatorname{adj} 1.11(95 \% \mathrm{Cl} 1.06-1.16))$. The relationship with socio-economic standing was mixed; with those in social rented accommodation or without access to a car being more likely to receive medication, while those in manual or routine occupations were less likely to be on medication. Residents with chronic poor mental health in the most rural areas were slightly less likely to be on medication than residents in urban areas (ORadj $0.94(95 \% \mathrm{Cl}$ 0.90-0.99)).

Migrants with poor mental health were less than one-third as likely as the settled community to be on psychotropic medication (OR 0.30 (95\% $\mathrm{Cl} 0.27-0.34)$ ), and this was little changed with full adjustment for the other demographic and socio-economic factors (OR adj $_{0.32}$ (95\% $\mathrm{Cl} 0.29$ 0.36)). Although high English language proficiency was associated with lower likelihood of receiving medication the relatively small numbers meant that this did not reach the conventional levels of statistical significance $\left(\mathrm{OR}_{\text {adj }} 0.81\right.$ (95\% $\left.\left.\mathrm{Cl} 0.58-1.14\right)\right)$. However, the likelihood of migrants receiving medication did not change when this measure was introduced into the model. 
Table 1: The likelihood of those with poor mental health receiving psychotropic medication: a comparison of migrants and the settled majority population. Results displayed as odds ratios (95\% confidence intervals)

\begin{tabular}{|c|c|c|c|c|}
\hline & $\begin{array}{c}n \\
\text { (\% on medication) }\end{array}$ & Model 1 & Model 2 & Model 3 \\
\hline Migrant Status (ref: Settled) & $76,531(86.0)$ & & & \\
\hline All Migrants & $1,736(66.7)$ & $0.32(0.29-0.36)$ & $0.33(0.29-0.36)$ & $0.32(0.29-0.36)$ \\
\hline Age (ref: $16-24)$ & $4,723(70.6 \%)$ & & & \\
\hline $25-34$ & $11,591(80.8 \%)$ & $1.63(1.50-1.76)$ & $1.62(1.50-1.76)$ & $1.45(1.33-1.58)$ \\
\hline $35-44$ & $18,847(86.6 \%)$ & $2.21(2.04-2.40)$ & $2.18(2.01-2.36)$ & $1.95(1.78-2.13)$ \\
\hline $45-54$ & $24,326(87.8 \%)$ & $2.33(2.14-2.53)$ & $2.25(2.07-2.44)$ & $2.00(1.83-2.19)$ \\
\hline $55-64$ & $18,700(88.2 \%)$ & $2.36(2.16-2.57)$ & $2.24(2.05-2.45)$ & $2.00(1.81-2.20)$ \\
\hline Sex (ref: Male) & $48,012(80.4 \%)$ & & & \\
\hline Female & 30,255 (89.0\%) & $1.93(1.85-2.01)$ & $1.93(1.86-2.02)$ & $1.95(1.87-2.03)$ \\
\hline Marital Status (ref: Married) & $29,191(88.8 \%)$ & & & \\
\hline Never Married & $27,279(80.1 \%)$ & $0.68(0.64-0.72)$ & $0.68(0.64-0.72)$ & $0.59(0.55-0.63)$ \\
\hline Separated/Divorced/Widowed & $21,797(88.8 \%)$ & $0.94(0.89-1.00)$ & $0.94(0.88-0.99)$ & $0.80(0.75-0.85)$ \\
\hline English Language (ref: Good) & $78,078(85.6 \%)$ & & & \\
\hline Poor & 189 (69.8\%) & & $0.91(0.65-1.26)$ & $0.81(0.58-1.14)$ \\
\hline Poor Physical Health (ref: Yes) & 35,925 (87.4\%) & & & \\
\hline No & $42,342(83.9 \%)$ & & & $1.11(1.06-1.16)$ \\
\hline NS - SEC (ref: Managerial) & $14,897(84.8 \%)$ & & & \\
\hline Intermediate & $9,571(86.8 \%)$ & & & $1.11(1.01-1.21)$ \\
\hline Small Employers & $4,796(84.2 \%)$ & & & $1.24(1.18-1.32)$ \\
\hline Routine/Semi-routine & $33,434(87.8 \%)$ & & & $0.96(0.90-1.03)$ \\
\hline Never Worked/Unemployed & $13,632(82.6 \%)$ & & & $0.81(0.71-0.91)$ \\
\hline Students & 1,937 (71.1\%) & & & $0.81(0.71-0.91)$ \\
\hline Car Availability (ref: 1 or more) & $51,309(85.8 \%)$ & & & \\
\hline 0 & $26,958(85.4 \%)$ & & & $1.07(1.00-1.14)$ \\
\hline Housing Tenure (ref: Owns) & $24,568(88.0 \%)$ & & & \\
\hline Private Renting & $15,781(84.4 \%)$ & & & $0.89(0.82-0.97)$ \\
\hline Social Renting & 37,918 (84.4\%) & & & $1.48(1.31-1.67)$ \\
\hline Urban - Rural Living (ref: Urban) & $56,584(85.7 \%)$ & & & \\
\hline Intermediate & $2,994(86.4 \%)$ & & & $1.06(0.95-1.18)$ \\
\hline Rural & $18,689(84.9 \%)$ & & & $0.94(0.90-0.99)$ \\
\hline
\end{tabular}

Model 1: adjusted for demographic characteristics

Model 2: plus adjustment for English language proficiency

Model 3: plus adjustment for chronic poor physical health and socioeconomic characteristics 
Table 2 shows that there was considerable variation in the likelihood of being on psychotropic medication within the different migrant populations. In all cases, with the exception of migrants from Germany, the migrant groups were much less likely than the settled population to be on psychotropic medication. Some migrant groups, most notably those from Central and Eastern Europe had amongst the lowest likelihood of being on medication): Poland (OR 0.13 (95\% Cl 0.10-0.17)); Lithuania (OR 0.09 (95\% Cl 0.05-0.14)); and other Central and Eastern Europe (OR 0.09 (95\% Cl 0.06-0.13)). Migrants from China and Hong Kong also had a very low likelihood of receiving at least one prescription (OR 0.12 (95\% $\mathrm{Cl} 0.07-0.20)$ ) during the follow-up period.

Table 2: Logistic regression analysis of psychotropic medication uptake over a period of 15 months for all migrants who had indicated a mental health problem in the 2011 Census of Northern Ireland, by region of birth. Results displayed as odds ratios ( $95 \%$ confidence intervals), adjusted for demographic factors, English language proficiency, poor physical health, and socioeconomic factors

\begin{tabular}{lllc}
\hline & \multicolumn{1}{c}{$n$} & \% Uptake & OR $(95 \% \mathrm{Cl})$ \\
\hline Migrant Status (ref: Settled) & 76531 & 86.0 & \\
Poland & 258 & 46.5 & $0.13(0.10-0.17)$ \\
Lithuania & 88 & 37.5 & $0.09(0.05-0.14)$ \\
India and South Asia & 69 & 65.2 & $0.26(0.15-0.43)$ \\
USA & 131 & 75.6 & $0.48(0.32-0.73)$ \\
Germany & 247 & 88.7 & $1.30(0.87-1.94)$ \\
North Africa and Middle East & 50 & 64.0 & $0.30(0.17-0.54)$ \\
C/E/W Africa & 97 & 77.3 & $0.50(0.31-0.81)$ \\
Southern Africa & 64 & 76.6 & $0.54(0.30-0.98)$ \\
The Americas/Caribbean & 142 & 76.1 & $0.50(0.33-0.74)$ \\
China and Hong Kong & 65 & 46.2 & $0.12(0.07-0.20)$ \\
C/E/SE Asia and E. Europe & 83 & 75.9 & $0.42(0.25-0.69)$ \\
Central and Eastern Europe (CEE) & 127 & 38.9 & $0.09(0.06-0.13)$ \\
Southern Europe & 160 & 73.8 & $0.41(0.28-0.59)$ \\
Northern and Western Europe & 63 & 71.4 & $0.41(0.23-0.71)$ \\
Oceania & 92 & 78.3 & $0.59(0.36-0.99)$
\end{tabular}

Sensitivity analyses found that likelihood of uptake of none of the three individual categories of medication (anxiolytics and hypnotics, antipsychotics, and antidepressants) were significantly different from the likelihood of uptake for all three together. Further sensitivity analysis concluded that changes in time allowed after census day to access medication (6, or 12 months) had no statistically significant difference on likelihood of uptake ((OR 0.33 ( $95 \% \mathrm{Cl} 0.30-0.37)$ ) and (OR 0.30 (95\% Cl $0.27-0.34)$ ), respectively). 


\section{DISCUSSION}

The principle finding of this study was that migrants in Northern Ireland who reported that they had a chronic mental health problem had a much lower likelihood of receiving a prescription for psychotropic medication than the settled population (OR $0.32(95 \% \mathrm{Cl} 0.29-0.36)$ ). This difference was not attributable to differences in demographic factors, physical health, socioeconomic factors or English language proficiency. The second finding was the heterogeneity amongst migrants with those from Central and Eastern Europe least likely to be in receipt of psychotropic medication, whilst migrants from Germany displayed levels of medication uptake closest to that of the settled population.

\section{Concordance with previous research}

To our knowledge this study is unique in comparing the treatment of poor mental health for migrant and settled populations. This study's other findings are largely concordant with previous research. The use of psychotropic medication increased with age, was lower in males and higher amongst those who were married ${ }^{4}$. The lower uptake in people reporting poor physical health may be due to the somatisation of mental health conditions ${ }^{31}$. The weak relationship between met need and socio-economic status mirrors the findings of the EU$\mathrm{WMH}^{\prime}$ s literature review and surveys ${ }^{4}$. The lower uptake in rural areas may be due to a combination of perceived stigma, reduced access to services, or lack of social support ${ }^{32}$.

Within Northern Ireland this variation would indicate a probable unmet need. We recognise that pharmacological treatment is not the recommended first-line management option for many psychiatric illness ${ }^{33}$, and that in theory such population-level differences may be due to variations in non-pharmacological treatment such as CBT. However, we do not believe this is a substantive explanation for the following reasons: the alternative modalities are not readily available; most people, including those on alternative management regimes, appear to also take some pharmacological medications, which is borne out of the very high overall treatment levels; and it is likely that the inclusion of these alternatives would accentuate rather than reduce the apparent differences (e.g. between men and women, or urban and rural areas). As discussed earlier, it is also possible that navigating the complexities of the healthcare system in the UK may be difficult for migrant populations - whilst English language proficiency did not appear to explain the levels of underuse of medications, factors such as the lack of understanding of the registration process and right to access may impede contact with the appropriate services ${ }^{13,14}$. However, it is not immediately clear that the lower uptake of medication amongst migrants is entirely due to unmet need for mental health care. 
Although there are likely to be commonalities between migrant groups and why they access medication at a different rate to the settled population, there are a number of distinct cultural differences unique to individual migrant groups that may affect medication uptake.

The three migrant groups with the lowest recorded use of psychotropic medication were from Poland, Lithuania, and other Central and Eastern European countries. Some research has indicated that the Polish population in the UK may exhibit high levels of mental health difficulties but low intentions for help-seeking men $^{34}$. It is well understood that alcohol is used as a coping mechanism for poor mental health, and the rates of harmful alcohol consumption in these countries may impact upon the uptake of psychotropic mediation ${ }^{35}$. Alternatively, within Northern Ireland, there is evidence that Polish migrants often prefer to return to Poland for treatment. In addition to obviating any language difficulties ${ }^{34}$, this would also circumvent the GP gatekeeping and long waiting lists within the UK and allows access to the consultant-led services in Poland ${ }^{6}$. Polish patients in the UK have generally good social networks ${ }^{36}$ and research suggests they may prefer to use talking therapies with Polish psychologists either in Northern Ireland or, via Skype, in Poland ${ }^{6}$. Furthermore, there is some evidence that antidepressants and other psychotropic medications can be obtained online following selfdiagnosis 6 .

Migrants from China and Hong Kong also had very low rates of psychotropic medication uptake. The low rates of medication uptake may be due to the way in which these migrants perceive mental health and the fact that suffering from mental illness is associated with a deep sense of shame in these societies ${ }^{8}$. It is thought that people in some societies tend to see mental illness as something that is happening 'within' them, that it takes the same form as a disease and is a biological condition. However, many migrants from countries such as China and Hong Kong are more likely to see mental illnesses as societal, and would attribute their mental ill-health to an external problem that is imparting ill-health onto them ${ }^{37}$. It therefore follows that these migrants would be less likely to access medical services. Should these migrants choose to seek help, the use of alternative medicines, such as Chinese Traditional Medicine (TCM), may be accessed instead. Though the scale of use of TCMs is unknown in Northern Ireland, a recent study in America found that 93\% of Chinese migrants had self-medicated (for non-specific conditions) using TCMs at least once ${ }^{38}$.

On the other hand, migrants to Northern Ireland from Germany displayed levels of psychotropic medication uptake comparable to the settled majority population. Whilst public attitudes towards medication, measured by way of population surveys, were less favourable in the 1990s, changes in representation in media, and influences of changing social environments has led to a significant increase in trust in the effectiveness of psychotropic medications ${ }^{39}$. 


\section{Limitations of the Study}

It is inevitable that, whilst high in quality and thought to cover the vast majority of the population, national registers will not account for every individual in the population. Therefore, it is likely that sections of the population that are most susceptible to mental ill-health (e.g. undocumented migrants). The study uses psychotropic medication uptake as the sole measure of mental health treatment. Whilst prescription medication is the primary treatment method for mental ill-health in Northern Ireland, persons in receipt of other treatments (e.g. talking therapies) may not be included in the study. In addition, whilst it is known that 'time since migration' can affect prevalence of mental ill-health for migrants, it was not possible to include this measure in the study due to ambiguity in the questions related to date of last migration in the 2011 Census of Northern Ireland.

\section{CONCLUSION}

This study shows that migrant populations who report chronic poor mental health in Northern Ireland have a considerably lower use of pharmacological treatment than the equivalent sufferers within the settled population. This likely represents a considerable degree of unmet need, and the precautionary principle suggests that there is a social responsibility to make changes to ease access to mental health care for migrants in light of this evidence.

The study also shows that there is a large amount of variation in the levels of unmet need between different migrant groups, owing to the heterogeneity within the migrant population. These results have implications for both research and policy. Firstly, they suggest a need for migrant groups, particularly those from Central and Eastern Europe, China, and Hong Kong, and those living in rural areas, to have better access to primary care mental health services. They also highlight a need for further research into individual migrant group attitudes towards mental health and health care access.

We suggest more qualitative studies to help reveal the reasons for the relatively low levels of psychotropic medication uptake amongst the majority of migrants. The results also highlight a need for changes in policy; whilst efforts have been made to ease migrants' access to healthcare (e.g. interpreters and translated signs inside healthcare facilities), there still exists a difference in the uptake of medication between migrants and the settled majority population. Improved service attempts at a primary care level may help to reduce this unmet need differential, perhaps through the implementation of initiatives akin to the 'English Improving Access to Psychological Therapies (IAPT)' initiative. IAPT was implemented to improve access to 
psychological therapies, and later pushed to ensure that access to mental health therapies are not hindered by ethnicity or culture ${ }^{28,40}$ Whilst the IAPT enjoyed only marginal success in England, it could be used as a good basis upon which to build specific primary care strategies in Northern Ireland. 


\section{ACKNOWLEDGMENTS}

The Administrative Data Research Network takes privacy protection very seriously. All information that directly identifies individuals will be removed from the datasets by trusted third parties, before researchers get to see it. All researchers using the Network are trained and accredited to use sensitive data safely and ethically, they will only access the data via a secure environment, and all of their findings will be vetted to ensure they adhere to the strictest confidentiality standards.

The help provided by the staff of the Administrative Data Research Network Northern Ireland (ADRC-NI) and the Northern Ireland Statistics and Research Agency (NISRA) Research Support Unit is acknowledged. The ADRC-NI is funded by the Economic and Research Council (ESRC). The authors alone are responsible for the interpretation of the data and any views or opinions presented are solely those of the author and do not necessarily represent those of the ADRC-NI. The BSO data has been supplied for the sole purpose of this project.

\section{CONTRIBUTORS}

KP, TB, AK, DOR and AV contributed to the study design. KP drafted the manuscript. All authors contributed to data interpretation and revising the manuscript content, and approved the final version of the manuscript.

\section{LICENSE OF PUBLICATION}

The Corresponding Author has the right to grant on behalf of all authors and does grant on behalf of all authors, an exclusive license (or non-exclusive for government employees) on a worldwide basis to the BMJ and co-owners or contracting owning societies (where published by the BMJ on their behalf), and its Licensees to permit this article (if accepted) to be published in Archives of Disease in Childhood and any other BMJ products and to exploit all subsidiary rights, as set out in our license.

\section{FUNDING}

The study was funded as part of an Administrative Data Research Centre Northern Ireland (ADRC-NI) research programme, funded by the Economic and Social Research Council (ESRC) (grants ES/L007509/1 and ES/S00744X/1). DOR, MD, and AK were also supported by the Medical Research Council (MRC) (grant MR/K023241/1). AK was additionally supported by the Academy of Finland (grant 312310 for the Centre of Excellence for Research on Ageing and Care, RG 3 Migration, Care and Ageing). 


\section{REFERENCES}

1. Byrne, P. Stigma of mental illness and ways of diminishing it. Adv. Psychiatr. Treat. (2000). doi:10.1192/apt.6.1.65

2. Vogel, D. L., Heimerdinger-Edwards, S. R., Hammer, J. H. \& Hubbard, A. 'Boys don't cry': Examination of the links between endorsement of masculine norms, self-stigma, and help-seeking attitudes for men from diverse backgrounds. J. Couns. Psychol. (2011). doi:10.1037/a0023688

3. Jordan, H., Roderick, P., Martin, D. \& Barnett, S. Distance, rurality and the need for care: Access to health services in South West England. Int. J. Health Geogr. (2004). doi:10.1186/1476-072X-3-21

4. EU contribution to the World Mental Health Surveys Initiative (EU-WMH). Social inequalities in mental health and in unmet need for mental health care in Europe. (2011).

5. Kirmayer, L. J. Cultural variations in the clinical presentation of depression and anxiety: implications for diagnosis and treatment. J. Clin. Psychiatry 62 Suppl 1, 22-30 (2001).

6. Kouvonen, A., Bell, J. \& Donnelly, M. 'We asked for workers but human beings came' Mental health and well-being of Polish migrants in Northern Ireland. (2014).

7. Miranda, J. Depression Prevalence in Disadvantaged Young Black Women. Soc Psychiatry Psychiatr. Epidemiol. 40, 253-258 (2005).

8. Lam, C. S. et al. Chinese Lay Theory and Mental IIlness Stigma: Implications for Research and Practices. J. Rehabil. (2010).

9. Chung, K. F. \& Wong, M. C. Experience of stigma among Chinese mental health patients in Hong Kong. Psychiatr. Bull. 28, 451-454 (2004).

10. Thorens, G., Gex-Fabry, M., Zullino, D. F. \& Eytan, A. Attitudes toward psychopharmacology among hospitalized patients from diverse ethno-cultural backgrounds. BMC Psychiatry 8, (2008).

11. Brisset, C. et al. Language barriers in mental health care: A survey of primary care practitioners. Journal of Immigrant and Minority Health 16, 1238-1246 (2014).

12. Priebe, S. et al. Good practice in health care for migrants: Views and experiences of care professionals in 16 European countries. BMC Public Health 11, (2011).

13. Business Servises Organisation. Entitlement to NHS Services and First Time Registration. Available at: http://www.hscbusiness.hscni.net/services/1814.htm.

14. Law Centre Northern Ireland. New Northern Ireland Regulations governing access to healthcare for migrants - A SUMMARY. (2015).

15. Reeves, M. et al. Access to health care for people seeking asylum in the UK. Br. J. Gen. Pract. 56, 306-308 (2006).

16. King's Fund. Access to health care and minority ethnic groups.

17. Salway, S. et al. Obstacles to 'race equality' in the English National Health Service: Insights from the healthcare commissioning arena. Soc. Sci. Med. 152, 102-110 (2016).

18. Grey, T., Sewell, H., Shapiro, G. \& Ashraf, F. Mental health inequalities facing U.K. minority ethnic populations: Causal factors and solutions. Journal of Psychological Issues in Organizational Culture 3, 146-157 (2013).

19. Chen, A., Kazanjian, A., Wong, H. \& Goldner, E. M. Mental health service use by Chinese immigrants with severe and persistent mental illness. Can. J. Psychiatry 55, 35-42 (2010). 
20. Fassaert, T. et al. Perceived need for mental health care among non-western labour migrants. Soc. Psychiatry Psychiatr. Epidemiol. 44, 208-216 (2009).

21. Bansal, N. et al. Disparate patterns of hospitalisation reflect unmet needs and persistent ethnic inequalities in mental health care: the Scottish health and ethnicity linkage study. Ethn. Health 19, 217-239 (2014).

22. Bell, M. L., Butow, P. N. \& Goldstein, D. Informatively missing quality of life and unmet needs sex data for immigrant and Anglo-Australian cancer patients and survivors. Qual. Life Res. 22, 2757-2760 (2013).

23. Bebbington, P. E., Marsden, L. \& Brewin, C. R. The need for psychiatric treatment in the general population: The Camberwell Needs for Care Survey. Psychol. Med. 27, 821-834 (1997).

24. McConnell, P., Bebbington, P., McClelland, R., Gillespie, K. \& Houghton, S. Prevalence of psychiatric disorder and the need for psychiatric care in Northern Ireland. Population study in the District of Derry. Br. J. Psychiatry 181, 214-9 (2002).

25. United Nations Statistics Division. Standard Country or Area Codes for Statistical Use. Available at: https://unstats.un.org/unsd/methodology/m49/.

26. Bramness, J. G., Walby, F. A., Hjellvik, V., Selmer, R. \& Tverdal, A. Self-reported mental health and its gender differences as a predictor of suicide in the middle-aged. Am. J. Epidemiol. 172, 160-166 (2010).

27. National Institute for Health and Care Excellence. Depression in adults: recognition and management.

28. Kirby, K. et al. A New Mental Health Service Model for NI: Evaluating the Effectiveness of Low Intensity CBT (LI-CBT) delivered in primary/community care settings.

29. Aware Northern Ireland. 1 in 6 Neople in Northern Ireland Are Using Anti-Depressant Medication. (2016).

30. thedetail.tv. The Script Report. (2014).

31. Al Busaidi, Z. Q. The concept of somatisation: A cross-cultural perspective. Sultan Qaboos University Medical Journal 10, 180-186 (2010).

32. Paykel, E., Abbott, R., Jenkins, R., Brugha, T. \& Meltzer, H. Urban-rural mental health differences in Great Britain: Findings from the National Morbidity Survey. International Review of Psychiatry 15, 97-107 (2003).

33. National Institute for Health and Clinical Excellence. Common mental health disorders: The NICE guideline on identification and pathways to care. The British Psychological Society and The Royal College of Psychiatrists (2011). doi:clinical guideline CG123.2011

34. Gondek, D. \& Kirkbride, J. B. Predictors of mental health help-seeking among polish people living the United Kingdom. BMC Health Serv. Res. 18, (2018).

35. Hammer, J. H., Parent, M. C., Spiker, D. A. \& World Health Organization. Global status report on alcohol and health 2018. Global status report on alcohol (2018). doi:10.1037/cou0000248

36. Galasinski, D., Sallah, D. \& Kozlowska, O. Migration, stress and mental health: an exploratory study of post-accession Polish immigrants to the United Kingdom. (2008).

37. Patel, V. Explanatory models of mental illness in sub-Saharan Africa. Soc. Sci. Med. 40, 1291-1298 (1995).

38. Wu, A. P. W., Burke, A. \& LeBaron, S. Use of traditional medicine by immigrant Chinese 
patients. Fam. Med. 39, 195-200 (2007).

39. Angermeyer, M. C. et al. The public debate on psychotropic medication and changes in attitudes 1990-2011. Eur. Arch. Psychiatry Clin. Neurosci. (2016). doi:10.1007/s00406015-0660-7

40. DH/Mental Health Division/APT. Commissioning IAPT for the whole community: Improving Access to Psychological Therapies. 